\title{
Abstracts of the meeting of the Clinical Genetics Society held on 22 and 23 September 1988 at the University of Aberdeen
}

\begin{abstract}
A regional register for familial adenomatous polyposis: congenital hypertrophy of the retinal pigment epithelium as a means of carrier detection

J BURN*, W CHURCH $\dagger$, P D CHAPMAN*, A GUNN $\ddagger$, J DELHANTY \&, AND D F ROBERTS*

Departments of Human Genetics* and Opthalmologyt, University of Newcastle upon Tyne; $\ddagger$ Department of Surgery, Ashington General Hospital; and §Galton Laboratory, London.
\end{abstract}

Familial adenomatous polyposis causes death and disability which may be avoided or prevented by an effective genetic register. Such a register has been established in collaboration with the surgeons of the Northern Region of England with a genetic nurse responsible for family tracing and monitoring of follow up bowel examinations. Twentyfive families containing 50 living affected subjects were identified in the first year of the study. Forty of the $\mathbf{5 0}$ obligate carriers agreed to have indirect ophthalmoscopy to search for congenital hypertrophy of the retinal pigment epithelium. Multiple lesions were found in all cases ranging from two to greater than 20 in number. This single physical sign allowed almost complete segregation of gene carriers from 40 normal controls. This sign further erodes the distinction between FAP and Gardner's syndrome and enhances linkage studies by permitting expansion of existing pedigrees. Paediatric practice may be modified, such that children who lack eye signs may be spared bowel examination until adulthood.

The Birmingham births study: ethnic group, consanguinity, and perinatal mortality

S BUNDEY, H ALAM, A KAUR, S MIR, AND R J LANCASHIRE Department of Clinical Genetics, Birmingham Maternity Hospital.

At the outset of a prospective study relating health in infancy and childhood to ethnic group, information was collected on parental ages, consanguinity, and perinatal mortality. Nearly 5000 babies were enrolled in the study: 2432 Europeans, 509 West Indians, 625 Indians, 956 Pakistans, 216 Bangladeshis, and some others. The Indian parents resembled the Europeans regarding sociodemographic and medical features. The West Indian parents tended to be young and unmarried; the Pakistani and Bangladeshi parents were older and had larger families. Of the European mothers, $0.4 \%$ were related to the fathers of their babies and the figures were $0.6 \%$ for West Indian mothers, $5 \cdot 1 \%$ for Indian mothers, $\mathbf{6 8} \cdot \mathbf{7} \%$ for Pakistani mothers, and $13.4 \%$ for Bangladeshi mothers. The peri- natal mortality rate was high for the Pakistani mothers but was significantly greatest for the offspring of consanguineous Muslim couples, in whose babies some autosomal recessive diseases could be recognised. It was interesting that lethal congenital heart malformations were equally common in the babies of non-consanguineous and consanguineous Muslims.

Matching HLA antigens significantly increases transplant survival: 20 years and 1001 kidneys in a search for genetic perfection

RODNEY HARRIS, PHIL DYER, SUSAN MARTIN, BOB JOHNSON, AND NETTER MALLIK

Departments of Medical Genetics, Surgery, and Renal Medicine, Manchester.

Since its beginning in 1968 the Regional Tissue Typing Service at St Mary's Hospital, Manchester has been responsible for matching and cross matching all organ allotransplants including kidneys, corneas, hearts, and livers. Of these, kidney transplants have greatly outnumbered the rest. To obtain minimum mismatch has required much labour including a 24 hour on call laboratory service and extensive kidney exchange with other regions and overseas. This search for genetic perfection has inevitably delayed transplant operations and lengthened ischaemic times as well as being expensive in a cash limited service. It has consequently been important to document the greatly superior $(p=0.004)$ transplant survival of well matched kidneys during the 20 years, culminating in a $91.1 \%$ survival at five years of 26 recipients with no HLA-B or DR mismatches compared with $55.1 \%$ in 69 recipients with three or four mismatches in the cyclosporin era. Matching is particularly valuable in recipients who have previously been highly sensitised by rejected transplants. Evidence for genetically controlled variation in transplant immunity is provided by significantly $(p=0.01)$ longer survival in HLA-DR1 positive compared with DR3 positive recipients. These outcome data are highly influential in health care policy making for the most effective treatment of end stage organ failure, as well as being a fascinating experiment in applied genetics.

A genetic study of facioscapulohumeral muscular dystrophy P W LUNT* AND P S HARPER $\dagger$

*St Mary's Hospital, Manchester; and +Institute of Medical Genetics, Cardiff.

From a clinical survey of 42 families the evidence for 
genetic heterogeneity, the expectation of severity, the age dependent penetrance, and the prospects for presymptomatic detection in facioscapulohumeral muscular dystrophy (FSHD) have been assessed. Variation between families in distribution of weakness and in previous diagnostic labelling was no greater than variation within a family. Over $50 \%$ of adult FSHD heterozygotes have significant lower limb weakness; 16 to $19 \%$ require a wheelchair by the age of 40 . Penetrance reaches $95 \%$ by the age of 20 . New dominant mutation could account for six isolated cases, all from non-consanguineous parents. CK was raised in only $36 \%$ of mildly affected women and $69 \%$ of men, but in 10/100 asymptomatic, at risk subjects raised CK could indicate a need for further investigation. Presymptomatic detection will be facilitated by successful mapping of the FSHD gene; linkage studies currently exclude its location from $20 \%$ of the genome.

Hereditary motor and sensory neuropathy type I (CharcotMarie-Tooth disease type I) is not linked to a chromosome 1 linkage group containing Dufiy (FY), amylase (AMY), tumour associated epithelial mucins (PUM), alpha-spectrin (SPTA), and serum amyloid protein (APCS)

SUE MALCOLM, HELEN MIDDLETON-PRICE, J BERCIANO, AND A E HARDING

Mothercare Department of Paediatric Genetics, Institute of Child Health, London; Hopital Nacional "Marquess de Valdechilla", Santanda, Spain; and Institute of Neurology, London.

We have established a linkage group extending from $A M Y$ in band 1p21 to SPTA within band 1q21. We have shown that $F Y$ is tightly linked to $P U M$ which maps, together with $S P T A$, within band 1q21. Linkage analysis in 12 families with hereditary motor and sensory neuropathy type I gave a lod score of -33.13 at $\theta=0.001$ and -4.45 at $\theta=0.10$ for linkage between $F Y$ and $H M S N I$, despite a previous report by Stebbins and Conneally of one family with a lod score of 3.11 at $\theta=0.05$ for linkage between these loci. There was also no linkage between $H M S N I$ and the other markers in the linkage group, thus excluding $H M S N I$ from $70 \mathrm{cM}$ of the pericentromeric region of chromosome 1 . Linkage to the chromosome 1 markers $M S 1, A P O A 2, A T 3, R E N$, and $M S 32$ and various candidate genes was also excluded.

Ocular myopathy with muscular dystrophy: an autosomal recessive kinship

J C S DEAN*, N HAITES*, P v BEST $\dagger$, AND A W JOHNSTON* Departments of Medical Genetics* and Pathologyt, Aberdeen University.

Kiloh and Nevin ocular myopathy is a heterogeneous group of disorders whose common feature is external ophthalmoplegia of myopathic origin. It is one part of the syndrome ophthalmoplegia plus. It has been suggested that mitochondrial abnormalities (often associated with autosomal dominant inheritance) may underlie ocular myopathies generally. We describe two sisters aged 36 and 24 who have an ocular myopathy associated with mild dystrophy of the facial muscles, sternomastoids, shoulder girdle, and upper limb muscles, including those of the thenar eminences. Onset was before the age of two years, but disease progression has been very slow. CK is normal or slightly raised and EMG non-specific. Muscle histology is that of a non-specific myopathy, and mitochondria appear normal. The pedigree suggests autosomal recessive inheritance. Although these cases resemble clinically some previously reported ocular myopathies, the biopsy findings and inheritance pattern differ.

The dysequilibrium syndrome

o W J QUARRELL AND H E HUGHES

Institute of Medical Genetics, University Hospital of Wales, Cardiff.

Hagberg et al (1972) defined dysequilibrium as ". . . . incapability or pronounced difficulty in maintaining posture and equilibrium, owing to defective postural reflexes." The syndrome was defined as "a non-progressive neurological condition dominated throughout childhood by incapability of, or pronounced difficulty in, maintaining an upright body position and in experiencing the position of the body in space . . . . ". We report a five year old boy, born to healthy, unrelated parents. Birth weight was $3460 \mathrm{~g}$ and the cord was around the neck but minimal resuscitation was required. The parents thought he was floppy. His motor milestones were significantly delayed and he still cannot walk unaided. Formal developmental assessments showed delay in all areas. A CT scan and extensive metabolic screen were normal. His two year old sister shows a similar pattern of developmental delay. Both children have features typical of dysequilibrium syndrome. The movement disorder characteristic of dysequilibrium syndrome will be shown with the use of a video and a review of published reports given.

A new chromosomal instability syndrome with tissue specific radiosensitivity

J R W YATES, A M R TAYLOR, R CARACHI, J B P STEPHENSON, E BOYD, AND D G YOUNG

Duncan Guthrie Institute of Medical Genetics and Royal Hospital for Sick Children, Glasgow; and Department of Cancer Studies, University of Birmingham.

We report a family in which two brothers were microcephalic and developed malignancies in early childhood. The first died at $\mathbf{1 5}$ months with two primaries: embryonal rhabdomyosarcoma of the ear and retroperitoneal ganglioneuroblastoma. The second was investigated for hypotonia and developmental delay. Chromosome analysis showed instability. Serum AFP was $156 \mathrm{ku} / \mathrm{l}$ (normal $<10$ $\mathrm{ku} / \mathrm{l})$. At 12 months a nephroblastoma necessitated nephrectomy. After the first course of vincristine and actinomycin $\left(1.5 \mathrm{mg} / \mathrm{m}^{2}\right)$ profound neutropenia suggested abnormal sensitivity to chemotherapy. Subsequent treatment was at one third normal dosage. Examination at two years showed head circumference 4 SD below the mean, sparse hair, strabismus, diffuse lens opacities, severe developmental delay, hypotonia, jerky optical pursuit, and 
absent optokinetic nystagmus in the horizontal plane. Cultured lymphocytes $X$ irradiated at $G_{2}$ (100 rads) showed gross excess of chromatid gaps and breaks compared with controls. In contrast, fibroblasts showed normal radiosensitivity. Similar studies in both parents were normal.

Linkage between $X$ linked deafness with stapes fixation and a cloned DNA sequence on the long arm of the $X$ chromosome

R BALLO, $\mathrm{C}$ WALLIS, G WALLIS, J GOLDBLATT, AND P BEIGHTON University of Capetown Medical School, South Africa.

$\mathrm{X}$ linked deafness with stapes fixation (DFN3) is a rare genetic disorder in which affected males have a mixed, progressive hearing loss. There is currently no reliable method for determining carrier status and no available prenatal diagnostic test. During a genetic survey on the island of Mauritius, DFN3 was diagnosed in a large kindred of Indian ancestry. Molecular linkage analysis was subsequently undertaken on 10 affected males, 11 unaffected males, and eight obligate carriers in three generations. The DNA probe pDP34 (DXYS1) was found to be tightly linked to the disorder with a lod score of 6.32 at zero recombination. These data indicate a locus for DFN3 in the Xq13-q21.1 region and have important implications for carrier detection and prenatal diagnosis in the affected kindred.

The use of molecular information at the retinoblastoma locus for genetic counselling and early diagnosis EBERHARD PASSARGE AND BERNHARD HORSTHEMKE Institut für Humangenetik, Universitätsklinikum Essen, FRG.

In a series of 60 unrelated patients with retinoblastoma screened by Southern blot hybridisation using appropriate DNA probes at or near the RB-1 locus, we found a heterozygous deletion in eight patients (seven bilateral, one unilateral multifocal retinoblastoma). In three patients the deletion could be detected by molecular analysis only, and in five it was also visible by light microscopy as an interstitial deletion involving the RB-1 locus. Transmission and new mutation could be distinguished, including determination of the parental origin of the mutation. In 12 families we could identify the parental chromosome 13 most likely to carry the mutation by linkage analysis and thereby provide an accurate prediction of the presence or absence of the mutation before clinical signs of tumour development. Thus, under appropriate circumstances, early therapy can be provided or frequent ophthalmological examinations under general anaesthesia avoided.

Long range mapping: a powerful method for analysing gene organisation at the duplicated 21-hydroxylase and complement $\mathrm{C} 4$ loci

SIMON COLLIER, PAUL J SINNOTT, PHILIP A DYER, RODNEY HARRIS, AND TOM STRACHAN
Department of Medical Genetics, St Mary's Hospital, Manchester.

We and others have inferred a high frequency of gene deletion in patients with 21-hydroxylase deficiency by conventional short range mapping techniques using 21-OH and C4 DNA probing of genomic Southern blots. The basis for such a high frequency of gene deletion has been presumed to be unequal crossover. Recent studies have suggested that there is also evidence for a high frequency of non-reciprocal transfer of sequence information by mechanisms resembling gene conversion and the authenticity of gene deletions as defined by short range mapping has subsequently been questioned. In order to address this problem, we have developed versatile long range mapping for analysing gene organisation at the $21-\mathrm{OH}$ and $\mathrm{C} 4$ loci by DNA probing of large restriction fragments on pulsed field electrophoresis gels. The basis of the method is to digest genomic DNA with a rare cutting restriction nuclease that has well conserved recognition sites flanking the 21-OH/C4 loci. DNA probing of the digested DNA with $21-\mathrm{OH}$ or C4 DNA probes shows one hybridisation band per haplotype. Using this approach we have confirmed a high frequency of gene deletion in $21-\mathrm{OH}$ deficiency families and our analyses on these and normal controls strongly support a model of gene expansion and contraction in this region owing to unequal crossover.

The evolution of a molecular genetic diagnostic service LINDA MEREDITH, MEENA UPADHYAYA, AND PETER S HARPER Institute of Medical Genetics, University of Wales College of Medicine, Cardiff.

The successive stages in development of the molecular genetics diagnostic service in Cardiff over a three year period are described. Of $\mathbf{4 0 5}$ completed diagnostic studies, $151(37 \%)$ related to carrier detection, $187(46 \%)$ to determination of informativeness for future prenatal diagnosis, and $67(17 \%)$ to prenatal diagnostic samples, these last being based on first trimester chorion biopsy in all but two cases. The principal disorders analysed included Duchenne and Becker muscular dystrophies (104 requests), Huntington's disease (80), cystic fibrosis (69), and myotonic dystrophy (51). DNA banking of samples represents a major activity (758 samples for 42 different disorders over a one year period). Problems and major issues regarding staffing, funding, and data maintenance are discussed and the importance of close integration with the clinical and other genetic services is emphasised.

Linkage of Friedreich's ataxia to human chromosome 9 JACQUI SHAW, SUSAN CHAMBERLAIN, ALISON ROWLAND, JULIE WALLIS, SALLY SOUTH, MARTIN FARRALL, AND BOB WILLIAMSON

Department of Biochemistry and Molecular Genetics, St Mary's Hospital Medical School, University of London.

Friedreich's ataxia is an autosomal recessive neurodegenerative disorder. The biochemical defect is unknown. We 
have undertaken genetic linkage studies to determine the chromosomal location of the mutated gene causing Friedreich's ataxia as a first step to the identification of the defective gene product. We have shown linkage of the mutation to the sequence defined by MCT112 (lod score of approximately 20 at a recombination fraction $\theta=0$ ) and interferon $\beta$, both mapping to chromosome 9 . The linkage data strongly suggest locus homogeneity. In the near future, extension of the linkage map to give fully informative markers will permit prenatal diagnosis, presymptomatic diagnosis, and carrier detection for families in which Friedreich's ataxia occurs.

\section{Linkage analysis in fragile X syndrome using DXS98}

I A GLASS* $\dagger$, L A PIRRIT*, F COCKBURN $\dagger$, R E SCHNUR $\ddagger$, R L NUSSBAUM $\ddagger$, AND J M CONNOR*

${ }^{*}$ Duncan Guthrie Institute of Medical Genetics and tDepartment of Child Health, Royal Hospital for Sick Children, Yorkhill, Glasgow G3 8SJ; and $\ddagger$ Department of Human Genetics and the Howard Hughes Medical Institute, University of Pennsylvania School of Medicine, Philadelphia.

Carrier detection in the fragile $\mathrm{X}$ syndrome by demonstration of the fragile site at Xq27.3 is of limited value and flanking polymorphic probes have so far been limited by the high rates of recombination observed within the Xq27-qter region. We have therefore evaluated $D X S 98$ (4D8) which detects an $M s p I$ polymorphism with alleles of $7.8 \mathrm{~kb}(\mathrm{f}=0.16)$ and $25 \mathrm{~kb}(\mathrm{f}=0.84)$. Twenty-four obligate carriers of 14 fragile $X$ families were screened and six were found to be heterozygous. In 10 informative meioses no recombinants were found, giving a peak lod score of 2.41 $(\theta=0)$. In two of the families with no recombination between FRAXA and DXS98, recombination had previously been recognised with the other flanking probes $D X S 15, D X S 52$, and $F 9$, supporting the conclusion that $D X S 98$ lay closer to FRAXA than these loci. These findings are consistent with the results of Brown et al (Lancet 1987;i:280) who found a peak lod score of 3.41 $(\theta=0.05)$ and suggest that 4D8 is a potentially useful adjunct for carrier detection in fragile $\mathrm{X}$ syndrome.

The use of minisatellite probes to study DNA damage in patients on chemotherapy

K ROSS, N HAITES, K KELLY, B BENNET, AND A DAWSON Departments of Medicine, and Genetics and Microbiology, University of Aberdeen.

DNA fingerprinting, using techniques established by Jeffreys, has been applied in a new way to non-Hodgkin's lymphoma patients receiving combination chemotherapy. Seven patients have been studied, six with non-Hodgkin's lymphoma (NHL) and one with Hodgkin's disease. In two patients with non-Hodgkin's lymphoma changes were observed in the DNA fingerprints during the course of therapy. In both patients, new bands were observed together with the disappearance of bands noticed in the control (pretreatment) samples. Up to four bands in the range 2 to $6 \mathrm{~kb}$ were affected. The study is continuing to determine whether or not these changes persist after completion of the chemotherapy regimen. In one NHL patient, chemotherapy has apparently affected the stability of the DNA in storage but this work remains to be confirmed. In the remaining four patients (three NHL, one $\overline{\bar{c}}$ Hodgkin's) no fingerprint changes were observed. In $\frac{\omega}{\overparen{D}}$

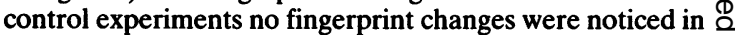
DNA samples stored for one year compared to fresh DNA, ڤ and repeated freeze-thaw cycles of DNA and blood did not affect the fingerprint. The significance of these results in. terms of response to treatment and implications for the $\vec{\overrightarrow{ }}$ induction of second primary malignancy will be explored.

Clinical and genetic aspects of Aarskog's syndrome M E PORTEOUS, D GOUDIE, AND J TOLMIE Glasgow.

Fifteen subjects with Aarskog's syndrome and 16 obligate 음 carriers were examined for features of the syndrome. The findings in affected males correlated well with previously $z$ published data. All the carrier females were below the 10 th centile for height and the majority were below the 3rd $\stackrel{\rho}{\supset}$ centile. Most showed either characteristic facial features or $\vec{\varphi}$ joint laxity. This might suggest $X$ linked dominant inheri- $\bullet$ tance. Intellectual development has been the subject of $\bullet$ some controversy. A detailed review of published reports $\square$ showed six out of 87 affected males to be mentally retarded (IQ less than 70). None of the males in our series is retarded and, combining previous data with our own, the incidence of mental retardation is shown to be not $\frac{\mathrm{Q}}{\mathrm{Q}}$ significantly greater than in the normal population.

A family with Ehlers-Danlos syadrome type IV: recessive or dominant?.

J C S DEAN, $F$ M POPE, $R$ PHILliPS, $N$ HAITES, AND A $W$ JOHNSTON

Department of Medical Genetics, University of Aberdeen, and Northwick Park Hospital, Harrow.

Ehlers-Danlos syndrome type IV is recognised to be clinically, biochemically, and genetically heterogeneous. Increasing knowledge of the biochemical abnormalities has not yet clarified the situation. The proband presented with a spontaneous left caroticocavernous fistula at the age of $D$ 27 and died two weeks later from a ruptured right internal 을. carotid artery aneurysm. Her brother, aged 29 , has $\mathrm{N}$ epilepsy and a number of carotid and other arterial or aneurysms. Both sibs have a characteristic facies and an $\mathrm{N}$ unusual skull shape with an occipital 'shelf'. Their parents N్ appear healthy in their middle to late fifties. Skin fibroblasts cultured from the brother fail to secrete type III $<$ procollagen normally and it is retained intracellularly. This abnormality has previously been associated with autosomal dominant inheritance, but apart from a suspicion that the brother's newborn son has similar facies, the clinical evidence suggests autosomal recessive inheritance. The proband's parents refused skin biopsy, but a sample from the new grandson in the near future may clarify his prognosis. If he is normal, the genetic counselling problem remains. 
Genital anomalies, polydactyly, and retinitis pigmentosa: a new syndrome?

S SIMPSON, P SMAIL, J DEAN, N HAITES, AND A W JOHNSTON Departments of Medical Genetics and Child Health, University of Aberdeen Medical School, Foresterhill, Aberdeen.

A family is presented who have features of perineoscrotal hypospadias in five males, distal vaginal atresia with vaginourethral fistula in one female, and ectopia vesica in another. Polydactyly is a feature in at least two members and retinitis pigmentosa affects one female. Autosomal dominant inheritance is postulated because of male to male inheritance. Clinical findings and the results of chromosome studies, endocrine investigations, and gonadal steroid receptor studies are not consistent with any known syndrome.

\begin{abstract}
Linkage analysis in a large family with non-specific $X$ linked mental retardation

I A GLASS ${ }^{*} \dagger$, L A PIRRIT*, F COCKBURN $\dagger$, AND J M CONNOR* *Duncan Guthrie Institute of Medical Genetics, and tDepartment of Child Health, Royal Hospital for Sick Children, Yorkhill, Glasgow G3 8AJ.
\end{abstract}

We have identified a large five generation family with non-specific $X$ linked mental retardation. There are nine living affected males who have IQs between 40 and 60 but no other abnormal clinical features, notably normal stature, facies, and testicular volume. Obligate carrier females were clinically normal and chromosomal studies including fragile $\mathrm{X}$ were normal in males and females. In an affected male and obligate carrier female flow cytometry was performed but showed no detectable reduction in the size of the $X$ chromosome. Linkage analysis was undertaken with $15 \mathrm{X}$ chromosomal RFLPs. The maximal lod score obtained has been 1.63 at a 0.09 recombination fraction for $F 9$ suggesting a tentative localisation to distal $\mathrm{Xq}$ for the disease gene in this family.

\section{Flanking markers for NF1}

M UPADHYAYA, M SARFARAZI, S M HUSON, W BROADHEAD, A FRYER, AND P S HARPER

Institute of Medical Genetics, Cardiff.

We have analysed 16 polymorphic DNA markers spanning region $17 p 11-17 q 24$ in 22 NF1 families. The family panel comprises 148 potentially informative meioses, 64 of which are phase known. Close linkage between NFI and eight pericentromeric markers (HHH202, EW206, CRI L946, EW203, EW301, FG2, p17H8, and CRI L581) is noted. Probe $\mathrm{HHH} 202$ was found to be the closest marker to $\mathrm{NFI}$. The study of multiply informative meioses suggests that the probes HHH202 and EW206 are flanking markers for NF1. The most likely order based on multiply informative meioses and multipoint mapping is: pter-p10-301-cen-202NF-206-207-qter.
An al (III) CB5 mutation in Ehlers-Danlos syndrome type IV

P NARCISI*, A C NICHOLLs*, A DE PAEPE $\dagger$, AND F M POPE* ${ }^{*}$ Medical Research Council, Clinical Research Centre, Harrow; and +Facultair Centrum voor Medische Genetica, Gent, Belgium.

We have previously shown genetic linkage of the collagen type III gene to Ehlers-Danlos syndrome type IV in a large, autosomal dominant, three generation Belgian pedigree with uninformative protein chemistry. Further studies have now identified a specific protein mutation in this family. Cyanogen bromide peptide mapping of the immunoprecipitated type III procollagen and collagen show both normal and shortened (mutated) $\alpha$ l (III)/CB5 peptides. This is consistent with a new methionine point mutation or a deletion within this peptide. Further experiments are in progress to clarify this matter.

Child outcome after midtrimester amniocentesis: development and physical status at four years of age

J K FINEGAN, B J QUARRINGTON, H E HUGHES, J E HOOD, J M MERVYN, J E ZACHER, AND M BOYDEN

Department of Psychology, The Hospital for Sick Children, Toronto, Ontario, Canada M5G 1 X8.

Our longitudinal study of children whose mothers had midtrimester amniocentesis has not shown negative developmental consequences in the neonatal period or at six months. Here we report the findings from reassessment of the children at four years of age. Children whose mothers had midtrimester amniocentesis $(n=88)$ did not differ from children whose mothers chose not to have amniocentesis $(n=46)$ on a range of psychological measures including intelligence, visual-motor-perceptual ability, language comprehension or expression, activity level, behaviour problems, social competence, or temperament. Group differences were not observed in height, weight, or head circumference. More mothers who had amniocentesis reported ear infections in their children $(p=0.04)$. Assessment by audiologists blind to the children's group showed a trend for a higher rate of bilateral abnormal middle ear impedance in children whose mothers had amniocentesis $(p=0.06)$. Possible mechanisms are presented.

Prospective prenatal screening for fetal abnormalities using a quantitative immunoassay for acetylcholinesterase LILIAS BARRON AND D J H BROCK Human Genetics Unit, University of Edinburgh.

An immunoassay based on a monoclonal antibody specific for acetylcholinesterase (AChE) was used prospectively over a two year period to screen second trimester amniotic fluids for fetal abnormalities. All 26 cases of spina bifida, three of which had normal $\alpha$ fetoprotein (AFP) concentrations and ultrasonar scans, were detected by the immunoassay. Four clear fluids, with abnormal AFP concentrations, had normal AChE titres and yielded normal 
outcomes. Some difficulties were encountered with both the AChE immunoassay and polyacrylamide gel testing when amniotic fluids were contaminated with old blood. However, the quantitative nature of the AChE immunoassay and its independence of operator experience make it an ideal adjunct to AFP assay for routine screening of amniotic fluids.

Chromosomal assignment of a tRNA gene cluster (tRNA ${ }^{\text {Leu }}$, tRNA $^{\text {Gin }}$, tRNA $^{\text {Lys }}$ ) to 17p12-pter

N MORRISON, J GODDARD, J M CONNOR, AND E BOYD

Duncan Guthrie Institute of Medical Genetics, Yorkhill, Glasgow.

Studies on the arrangement of human tRNA genes have shown that some may occur as solitary genes while others are present in clusters. We have investigated the chromosomal location of one such cluster containing genes for tRNA $^{\text {Leu }}$, tRNA $^{\text {Gln }}$, and tRNA ${ }^{\text {Lys }}$. In situ hybridisation with biotin labelling was carried out on lymphocyte cultures from human males of normal karyotype and the cluster was located to the distal short arm of chromosome 17. Preliminary studies suggest that this tRNA gene cluster is located on the long arm of chromosome 19 in gorilla, and on the short arm of chromosome 19 in orang-utan, providing further evidence for homology between chromosome 19 of the higher primates and chromosome 17 in man.

Linkage analysis in tuberous sclerosis with multiple markers from chromosome 9

J R SAMPSON*, L A PIRRIT*, P FLEURY $\dagger$, P BEIGHTON $\ddagger$, J R W YATES§, AND J M CONNOR*

${ }^{*}$ Duncan Guthrie Institute of Medical Genetics, Glasgow; tDepartment of Paediatrics, University of Amsterdam, Netherlands; $\ddagger$ Department of Human Genetics, Capetown University, South Africa; and §Department of Pathology, University of Cambridge.

In rigorously assessed UK families with tuberous sclerosis (TS), studies have indicated linkage of the disease locus (TSC) to the marker group $A B O, A B L, A K 1$ which maps to $9 \mathrm{q} 3.4$. Others have been unable to support this finding and genetic heterogeneity has been suggested. Our investigation has been extended by recruitment of further rigorously assessed families and by use of further probes from distal 9q. Recombination fractions ( $\theta \mathrm{m}$ and $\theta \mathrm{f})$, between markers and TSC, corresponding to maximum lod scores $(\hat{Z})$ were, for $A B L \quad \hat{Z}=2.98$ at $\theta \mathrm{m}=\theta \mathrm{f}=0.08$; for $A B O \hat{\mathrm{Z}}=0.86$ at $\theta \mathrm{m}=\theta \mathrm{f}=0.1$; for MCT136 $\hat{\mathrm{Z}}=1.14$ at $\theta \mathrm{m}=0.16$ and $\theta \mathrm{f}=0.2$; and for $\mathrm{EFD} 126.3 \quad \hat{\mathrm{Z}}=1.47$ at $\theta \mathrm{m}=0 \cdot 3$ and $\theta \mathrm{f}=0 \cdot 25$. Seven recombination events in meioses informative for TS and two or more markers excluded $T S C$ from the region distal to $A B L$ except for the interval MCT136- $A B O$. Multipoint analysis indicated the most probable position for $T S C$ to be some $10 \mathrm{cM}$ proximal to $A B L(\hat{\mathrm{Z}}=4 \cdot 4)$. However, in two of ten families free recombination between the $9 \mathrm{q}$ markers and $T S C$ was observed and more data are needed to clarify the question of heterogeneity.
A survey of manifesting carriers of Duchenne and Becket: muscular dystrophy in Wales

ANDREW NORMAN AND PETER HARPER

Institute of Medical Genetics, University of Wales Colleg of Medicine, Cardiff.

Manifesting carriers of Duchenne and Becker musculaß dystrophy are uncommon but well described. Such patienty are of particular interest with regard to the differential diagnosis from autosomal recessive limb-girdle dystrophy? All mothers of affected males known to the genetic registe $L$ for Wales, which has been kept for the past 10 years, wer乡山 contacted and 167 out of a possible 190 were examined. I. was estimated from pedigree and creatine kinase analysię that 119 out of the 167 were carriers of the Duchenne Becker gene. Three manifesting carriers were identified? giving a prevalence of $3 / 119=2.5 \%$. During the period of the survey other women with very similar clinical finding but without an appropriate family history were referred to us. We strongly suspect some of these are also manifesting carriers of the DMD/BMD gene.

Dystrophin gene deletions in males diagnosed as spinaP muscular atrophy

P W LUNT, H KINGSTON, A P READ, R C MOUNTFORD, AN R HARRIS

Department of Medical Genetics, St Mary's Hospita Manchester.

Seven unrelated males with limb-girdle weakness, cali hypertrophy, and high CK, in whom spinal musculaø atrophy had previously been diagnosed, were tested fo? DNA deletions within the dystrophin gene using $\mathrm{cDN} \overrightarrow{\widehat{A}}$ probes. Five had a family history compatible with linkage and two were isolated cases. Deletions were ident? fied in four cases (three familial, one isolated) establishing. the diagnoses as Becker muscular dystrophy (BMD). The existing clinical diagnosis was given support in the tw familial non-deletion cases by observing recombinatiog between the disease locus and RFLPs identified by pERT87 probes closely linked to BMD. We suggest thät evaluation of males with limb-girdle weakness and caf hypertrophy should include DNA studies, as our results highlight the difficulties with diagnostic interpretation of some EMG, CT scan, and muscle biopsy findings. Futur use of direct gene probes and assay of encoded protein should assist in classification of these and other neuro muscular syndromes.

Carrier estimations and deletion mapping in DMD families in Northern Ireland

E D KELLY, C A GRAHAM, P MORRISON, AND N C NEVIN 0 Department of Medical Genetics, Queen's University Belfast.

DNA analysis was carried out on 25 out of 60 DMळ families in Northern Ireland to provide risk estimations of possible carrier females and to study deletions in affecte males. Definite carriers and mothers of affected boys were screened initially for informativeness with pERT and X 
probes and 34/38 (94\%) were informative for at least one probe. Risks have been calculated before and after RFLP analysis using MLINK for 52 possible carrier females from 15 families. Of these 27 had their risk reduced below $6 \%$, three remained unchanged, and seven had their risk increased above $85 \%$. Forty-three males affected with DMD have been tested for DNA deletions with pERT and 754 probes and the cDNA probes cf56a and cala. The results are shown below.

\begin{tabular}{clcc}
\hline Probe & $\begin{array}{l}\text { No of } \\
\text { samples }\end{array}$ & $\begin{array}{l}\text { No of } \\
\text { deletions }\end{array}$ & \% deletions \\
\hline pERT $87-1$ & 41 & 1 & $2 \cdot 4$ \\
$87-8$ & 41 & 1 & $2 \cdot 4$ \\
$87-15$ & 40 & 2 & $5 \cdot 0$ \\
754 & 42 & 0 & 0 \\
cf56a & 43 & 18 & $42 \cdot 0$ \\
cala & 43 & 2 & $6 \cdot 0$ \\
\hline
\end{tabular}

DNA probing in dystrophia myotonica in Scottish families C CLARK, $\mathrm{K}$ F KELLY, $\mathrm{N}$ E HAITES, J DEAN, AND A W JOHNSTON

Departments of Genetics and Microbiology, Medical School, University of Aberdeen.

Through the Scottish Molecular Genetics Consortium, 15 families affected by dystrophia myotonica have been analysed in Aberdeen. A total of 90 subjects (52 affected) has been studied using up to four probes and 10 polymorphisms. Most of the families have been made informative using the APOC2 probe and the polymorphisms BanI, TaqI, and NcoI. In one case, probing with all available probe/polymorphism combinations has failed to make a subject informative, while in another case polymorphisms determined with probes LDR 152 and PJSB 6 were used in combination with the MLINK program to provide an exclusion probability. These two cases are illustrated. The estimated number of affected subjects in Scotland is about 275 , based on a prevalence of 5 per 100000 . Through the work of the Scottish Molecular Genetics Consortium, 20\% of these have already been identified and their DNA examined.

A study of West Midlands cystic fibrosis families with five linked DNA probes

CAROL HARDY AND PETER FARNDON

Clinical Genetics Unit, Birmingham Maternity Hospital.

Thirty-nine families from the West Midlands region with at least one child affected with cystic fibrosis have been typed with five DNA probes, namely met D (TaqI), met $\mathrm{H}$ (TaqI), XV2c (TaqI), KM.19 (PstI), and J3.11 (MspI). Using this combination of probes, 36 families $(92 \%)$ are fully informative. In each of the remaining three families one of the parents is homozygous for all of the polymorphisms tested. The most useful probe is KM.19 for which $44 \%$ of our families are fully informative. The most productive strategy for typing the families is first to apply the probes KM.19 (PstI) and XV2c (TaqI), and then simul- taneously to probe the TaqI blot with met D and met $\mathrm{H}$. Families which are not fully informative after these steps can be typed with $\mathrm{J} 3.11(\mathrm{MspI})$. The strong linkage disequilibrium that exists between the markers KM.19 and $\mathrm{XV} 2 \mathrm{c}$ and the CF locus has enabled high and low risk haplotypes to be defined.

Linkage disequilibrium between probes XV2c/KM19 and cystic fibrosis in Northern Ireland

A J M HILl, C A GRAHAM, D McLAVERTY, AND N C NEVIN Department of Medical Genetics, Queen's University, Belfast.

Polymorphic DNA probes XV2c and KM19 map very closely to the cystic fibrosis mutation and have been shown to exhibit strong linkage disequilibrium with cystic fibrosis in several populations. We have studied allele frequencies and haplotypes for these markers in $68 \mathrm{CF}$ families as shown below.

\begin{tabular}{|c|c|c|c|c|c|c|}
\hline & & \multicolumn{2}{|l|}{ Allele } & & \multicolumn{2}{|c|}{ Haplotypes } \\
\hline & & $\begin{array}{l}1 \text { (large) } \\
(\%)\end{array}$ & $\begin{array}{l}2(\text { small }) \\
(\%)\end{array}$ & & $\begin{array}{l}C F \\
(\%)\end{array}$ & $\begin{array}{l}\text { NOR } \\
(\%)\end{array}$ \\
\hline KM19 & $\begin{array}{l}\text { CF } \\
\text { NOR }\end{array}$ & $\begin{array}{l}29 \\
65\end{array}$ & $\begin{array}{l}71 \\
35\end{array}$ & $\begin{array}{l}\mathrm{K} 2 \mathrm{X} 1 \\
\mathrm{~K} 1 \mathrm{X} 1 \\
\mathrm{~K} 1 \mathrm{X} 2\end{array}$ & $\begin{array}{l}65 \\
15 \\
12\end{array}$ & $\begin{array}{l}19 \\
23 \\
42\end{array}$ \\
\hline XV2c & $\begin{array}{l}\text { CF } \\
\text { NOR }\end{array}$ & $\begin{array}{l}80 \\
45\end{array}$ & $\begin{array}{l}20 \\
55\end{array}$ & $\mathrm{~K} 2 \mathrm{X} 2$ & 8 & 16 \\
\hline
\end{tabular}

These figures are similar to those previously reported and suggest that haplotype analysis may prove useful in assessing carrier risks for $\mathrm{CF}$ in this population. It has been suggested recently that there is preferential inheritance of the paternal male CF allele. If this is so one would expect to find an increased male:female ratio in affected subjects. Of 78 affected subjects, $48(61 \cdot 5 \%)$ are males and 30 $(38.5 \%)$ are females. Of the homozygous normal sibs of these affected persons, five are male and four female while of the 21 heterozygous (carrier) sibs 12 are male (11 with the paternal CF allele) and nine are female (eight with the paternal CF allele). Nineteen of the $21 \mathrm{CF}$ carriers, therefore, have inherited the paternal CF allele, suggesting preferential paternal inheritance, although this is not specific to the male gamete.

Use of linkage disequilibrium data in prenatal diagnosis of cystic fibrosis

LISA STRAIN, ANN CURTIS, MOIRA MENNIE, SUSAN HOLLOWAY, AND D J H BROCK

Human Genetics Unit, University of Edinburgh.

Parents at risk of bearing a child with cystic fibrosis, and who have no living affected child, often use prenatal diagnosis based on microvillar enzyme assay in second trimester amniotic fluid samples. If enzyme levels are abnormal and the pregnancy is terminated, it is possible in principle to use the fetal tissues to establish the phase relationship of linked DNA markers for a subsequent first 
trimester prenatal diagnosis. However, the probability of a fetus being affected after an abnormal microvillar enzyme test may be no greater than $80 \%$. The strong linkage disequilibrium between haplotypes at the $D 7 S 23$ locus and the cystic fibrosis gene may be used to increase this probability. If fetal tissues are homozygous for the $6.6 \mathrm{~kb}$ band defined by pKM.19 and PstI and also homozygous for the $2 \cdot 1 \mathrm{~kb}$ band with $\mathrm{pXV} 2 \mathrm{c}$ and TaqI, the chance of being affected increases from $80 \%$ to between $95 \%$ and $97 \%$. We regard this as being sufficiently certain for use in phase determination.

\section{Applications of the polymerase chain reaction to cystic} fibrosis

A J IVINSON*, R G Elles*, A P READ*, M SCHWARZ $\dagger$, C WILlIAMS $\ddagger$, B WILlIAMSON $\ddagger$, AND R HARRIs*

*Regional Molecular Genetics Laboratory, Manchester; †Royal Manchester Children's Hospital; and $\ddagger S t$ Mary’s Hospital, London.

We present and discuss our data on the unusual segregation of the cystic fibrosis (CF) allele in carriers of the disease, which show that 21 out of 29 heterozygotes carrying the paternal CF chromosome are boys and 20 out of 31 heterozygotes carrying the maternal CF chromosome are girls.

These results are being extended by the use of primers for a Y chromosome repeat sequence for sexing chorionic villus samples and KM19 and CS7 primers for typing samples using the polymerase chain reaction (PCR). This work is part of our active programme for developing the PCR technique as a diagnostic tool for use in regional molecular genetics laboratories as well as a research tool. We report on how this rapid and accurate technique for amplifying selected areas of the genome has been developed for use in the prenatal diagnosis of CF. We discuss the benefits of a PCR amplification diagnosis compared to a conventional Southern analysis, which has enabled a seven to 14 day prenatal diagnosis to be reduced to one to two days. Results of amplifications using less than 10 white blood cells as the target DNA are shown, as are results of amplifications using dried blood spots, buccal cells, and pin prick spots of fresh blood, all of which provide ample target DNA for more than 30 separate PCR tests. The possible applications of this technique are discussed.

\section{T cell receptor $\beta$ chain polymorphism is associated with $\mathrm{CF}$} carriers

S A MCMILLAN*, A J M HILL $\dagger$, AND C A GRAHAM $\dagger$

*Regional Immunology Laboratory, Belfast City Hospital; and †Department of Medical Genetics, Queen's University, Belfast.

We investigated the $T$ cell receptor constant $\beta$ chain (TCR $c \beta)$ genes of cystic fibrosis carriers using a TCR $c \beta$ probe which recognises a $B g I I I$ polymorphism. We found that the frequency of the heterozygous genotype in CF carriers is $77 \%$ compared to a frequency of $43 \%$ in the controls. Increased frequency of the heterozygous genotype for this probe has previously been described in patients with certain autoimmune disorders (for example, insulin dependent diabetes and Graves' disease) and has been associated with HLA-DR3 typing. The TCR $c \beta$ gene h been localised to $7 \mathrm{q} 32,20$ to $30 \mathrm{cM}$ from the CF locis. These results would appear to represent a previousty unknown disease association but are not suggestive $\overline{\bar{\omega}}$ linkage disequilibrium between the CF locus and TCR $\overline{\text { 雨 }}$ genes as the allele frequencies are similar in both groups.

Prenatal exclusion testing for Huntington's disease using the polymerase chain reaction

I McINTOSH, ANN CURTIS, F A MILLAN, AND D J H BRo@ Human Genetics Unit, University of Edinburgh.

The use of the polymerase chain reaction (PCR) to ampliff genomic DNA by a factor of 10 or more makes it possibise to do analyses on very small chorionic villus samples inia few hours. We report a case of a fetus at risk for Huntington's disease (HD) where prenatal testing wes carried out within a working day by using the PCR to amplify a polymorphic DNA sequence adjacent to the $H \bar{P}$ locus. The risk of the fetus inheriting the HD gene coutr not be excluded and the pregnancy was terminated. This represents the first example of gene tracking by using amplification of a restriction fragment length polymorpto ism at some distance from the relevant mutation.

Presymptomatic testing for Huntington's disease: a case complicated by intragenic recombination within the $D 4 S \overline{D T}$ locus

. ANN CURTIS, F MILLAN, SUSAN HOLLOWAY, MOIRA MENN再, AILEEN CROSBIE, J A RAEBURN, AND D J H BROCK Human Genetics Unit, University of Edinburgh.

We report an unusual case of recombination betwe $\overrightarrow{7}$ restriction fragment length polymorphic sites within the D4S10 (G8) locus which confounded attempts to carry oft predictive testing for a person with a $50 \%$ risk of inheritiog the Huntington's disease (HD) gene. The family was fuly informative for the HindIII site 1 and PstI polymorphisn both of which are known to be centromeric to $H D$. If the gene order is $H D$-HindIII-PstI, recombination must have occurred in a maternal meiosis and the risk of the consultand inheriting the HD gene is $79 \%$. If the gene order is HD-Pst $\mathrm{I}$-HindIII, recombination could has occurred in either paternal or maternal meioses and t $\mathrm{Ee}$ risk remains close to $50 \%$. This case also illustrates one bof the weaknesses of carrying out predictive testing using DNA markers (G8 and subclones) which have an appres ciable recombination rate with the $\mathrm{HD}$ gene.

Definition of a chromosomal breakpoint near to the Huntington's disease locus

A DODGE AND A P READ

Department of Medical Genetics, St Mary's Hospitat, Manchester.

We have previously described a woman with a balance reciprocal translocation $46, X X, t(4 ; 12)(\mathrm{p} 16 ; \mathrm{p} 13.3)$ who had two children with Wolf-Hirschhorn syndrome. Studies 
with the G8 probe showed that the breakpoint lay distal to the D4S10 locus, unlike in other cases of Wolf-Hirschhorn syndrome described by Gusella's group. New results with the more distal probe Xp500 (defining the D4S43 locus) show that the breakpoint lies between D4S10 and D4S43. Within the family this permits prenatal diagnosis, difficult previously because of the extremely small cytogenetic change. Defined breakpoints in the distal part of $4 p$ are helpful for mapping the Huntington's disease locus, and cell lines have been made available to investigators.

Familial Wolf-Hirschhorn syndrome resulting from reciprocal translocation

D COUZIN, R RANKIN, AND J WATT

University of Aberdeen.

The index case was a dysmorphic baby delivered by elective caesarian section following intrauterine growth retardation. The child, a female, was noted to have microcephaly and exophthalmos with congenital cataracts. The head had a distinct 'Greek helmet' appearance. Chromosome studies of the mother and child suggested a karyotype of $46, \mathrm{XX}, \operatorname{der}(4), \mathrm{t}(4 ; 14)(\mathrm{p} 16.1 ; \mathrm{q} 31)$ mat. It seems likely that the $\mathrm{G}$ dark band $14 \mathrm{q} 31$ is split. Consequently there is a deletion of the region 4 (pter $\rightarrow$ p16.1) giving rise to the Wolf-Hirschhorn stigmata observed. The concomitant duplication of region $14(\mathrm{q} 31 \rightarrow \mathrm{qter})$ appears to have no phenotypic effect. A second pregnancy was terminated after amniocentesis. The similarity between this fetus and the index case is illustrated.

Genetic counselling difficulties with duplication and deficiency of $18 p$

J TOLMIE, E BOYD, E DUfFIE, J COLGAN, J R W YATES, AND A COOKE

Duncan Guthrie Institute of Medical Genetics, Glasgow.

A child with mild mental handicap and short stature was discovered to have inherited an abnormal chromosome 18 , $\operatorname{del}(18)(\mathrm{p} 11.3 \rightarrow$ pter) from his apparently normal mother. His maternal grandparents had normal karyotypes. Cytogenetic studies failed to show any other chromosome rearrangement in the mother and flow karyotype studies in the mother and child showed in both cases that one homologue of chromosome 18 was reduced in size by $10.5 \%$ compared with normal. In a second family $3: 1$ segregation at meiosis gave rise to two persons with dup(18p) who were the offspring of balanced translocation carriers $t(13 ; 18)(q 12.1 ; p 11.2)$. One subject was an apparently normal, fertile male while the other was a normally grown female infant when last examined at the age of three months. These two families indicate that abnormalities of $18 p$ may have minimal phenotypic effect and thus pose difficulties for genetic counselling.

Linkage study of a Scottish family segregating for $\mathbf{X}$ linked Charcot-Marie-Tooth disease (CMTX)

NICHOLAS FAIRWEATHER, KEVIN KELLY, NEVA HAITES, SHEILA SIMPSON, CAROLINE CLARK, AND ALAN JOHNSTON Department of Genetics and Microbiology, University of Aberdeen.

The $\mathrm{X}$ linked form of Charcot-Marie-Tooth disease seen in this single family has been shown to be linked to DXYS1 by virtue of a lod score of 4.551 at a recombination fraction of 0.03 and to $P G K 1$ with a lod score of 3.34 at zero recombination. This confirms previous work. Pooled data from our family and seven previously reported families give a maximum lod score of 12.04 at a $\boldsymbol{\theta}_{\max }$ of $\mathbf{0 . 0 5}$ for linkage between CMTX and DXYS1 loci.

Application of in situ hydridisation to diagnostic cytogenetics

M E FERGUSON-SMITH, S S M HABEEBU, D SPATHOS, AND M A FERGUSON-SMITH

Cytogenetics Unit, East Anglian Regional Genetics Service, Deparment of Pathology, Cambridge.

The origin of de novo unbalanced duplications can be a diagnostic dilemma if the duplication is too small to have a characteristic banding pattern. In situ hybridisation, using chromosome specific DNA probes on standard air dried chromosome preparations, can be used for this purpose but the prolonged exposure time for autoradiography, using radioisotopic probes, reduces the applicability of the method, particularly when several DNA probes are required. Improved techniques using biotin labelled probes and reflectance contrast microscopy allow results to be obtained within 48 hours even for single gene copy DNA sequence. A biotinylated Y specific sequence GMG $\mathrm{Y} 10$ was used to identify an obvious $\mathrm{Xp}$ duplication in a phenotypic male with infertility and features of Klinefelter's syndrome as an X-Y interchange. This diagnosis was achieved within six days of receiving the first blood sample. 